\title{
Perspectiva educativa do cuidado de enfermagem sobre a manutenção da estomia de eliminação
}

\author{
Educational perspective on nursing care about the maintenance of elimination ostomy
}

Perspectiva educacional de la atención de enfermería acerca de la manutención de la estomía de eliminación

\author{
Paula Alvarenga de Figueiredo Martins', Neide Aparecida Titonelli Alvim' \\ 'Universidade Federal do Rio de Janeiro. Escola de Enfermagem Anna Nery. Rio de Janeiro, RJ
}

Submissão: 19/01/2010 Aprovação: 17/10/2010

\section{RESUMO}

Este estudo foi desenvolvido com os objetivos de descrever os saberes e práticas de usuários estomizados sobre a manutenção da estomia de eliminação intestinal e urinária; e analisar a pertinência do compartilhamento de tais saberes e práticas com os cuidados fundamentais de enfermagem, desenvolvidos no contexto ambulatorial. Tratou-se de pesQuisa Qualitativa do tipo convergente-assistencial. Utilizou-se um formulário de identificação do estomizado e uma entrevista semi-estruturada para produção de dados. Os aspectos éticos foram atendidos. A pesQuisa revelou a necessidade de maior divulgação sobre a realidade concreta desses usuários para Que possam sentir-se mais acolhidos, fortificados no enfrentamento das dificuldades Que, porventura, surjam no cotidiano de con(viver) com a derivação cirúrgica.

Descritores: Enfermagem; Educação em saúde; Estomia; Assistência ambulatorial.

\section{ABSTRACT}

This research aimed to describe ostomized users' knowledge and practices with regard to the maintenance of an intestinal and urinary elimination ostomy; and to analyze the pertinence of sharing this knowledge and practice with fundamental nursing care in an outpatient context. The Care-Converging Research method was employed. A form was used to identify to ostomized patient and a semistructured interview to produce the data. All ethical aspects were complied with. The research revealed the need for further dissemination about these users' concrete reality, so that they can feel more welcomed, strengthened to cope with difficulties that may arise in their daily reality of living with the surgical derivation.

Key words: Nursing; Health education; Ostomy; Ambulatory care.

\section{RESUMEN}

Las finalidades de este estudio fueron describir los saberes y prácticas de usuarios ostomizados sobre la manutención de la ostomía de eliminación intestinal $y$ urinaria; $y$ analizar la pertinencia del compartimiento de tales saberes y prácticas con los cuidados fundamentales de enfermería, desarrollados en el contexto ambulatorio. El método empleado fue la Investigación Convergente-Asistencial. Fue utilizado un formulario de identificación del ostomizado y una entrevista semiestructurada para producción de datos. Los aspectos éticos fueron cumplidos. La investigación reveló la necesidad de mayor divulgación sobre la realidad concreta de esos usuarios para que puedan sentirse más acogidos, fortificados en el afrontamiento de las dificultades que talvez surjan en el cotidiano de con(vivir) con la derivación Quirúrgica.

Descriptores: Enfermería; Educación en salud; Ostomía; Atención ambulatoria.

\footnotetext{
AUTOR CORRESPONDENTE Paula Alvarenga de Figueiredo Martins. Rua Dr. Sílvio Bastos Tavares, 348. Bloco I20/Apto 304. CEP 2805 I-250.

Campos dos Goytacazes, RJ. E-mail: eaepaula@yahoo.com.br
} 


\section{INTRODUÇÃO}

Desde o início do curso de Graduação em Enfermagem vivenciamos diversas experiências educativas junto ao usuário em diferentes cenários de prática profissional. A cada período do curso construíamos novas maneiras de abordar o usuário de acordo com suas necessidades específicas. Essas experiências permitiram-nos principalmente a reflexão sobre a prática de educação em saúde articulada ao cuidado fundamental de enfermagem no espaço hospitalar, como também as possibilidades de intercâmbio entre o saber técnico-científico ou profissional e o saber popular advindo do senso comum.

Posteriormente, tivemos o nosso primeiro contato com o usuário estomizado ${ }^{\text {a }}$ Pudemos desvendar as alterações decorrentes da confecção do estoma incluídas na dimensão biopsicosocioespiritual desse usuário, levando-nos à reflexão de Que, para desenvolvermos uma adequada assistência a este usuário devemos incluir além do aporte técnico e apoio psicológico, um plano de educação em saúde no intuito de colaborar com o desenvolvimento de habilidades da pessoa no cuidado de si.

Na condição de educadora em saúde, a enfermeira precisa conhecer a realidade na Qual se situa o usuário, devendo resgatar esse sujeito como cidadão participante do seu processo de cuidado, através do diálogo, possibilitando desta forma, a transição de uma consciência "ingênua”, caracterizada pela passividade, para uma consciência crítica e reflexiva, capaz de colocá-lo em posição Questionadora, participativa e ativa. Isto significa Que os usuários devam assumir a posição de sujeitos e não objetos da ação profissional. Assim agindo, podem optar por aderir ou não à mudança de hábitos, atitudes e modos de pensar a vida e a saúde. Desta maneira, a enfermeira constrói conjuntamente com os usuários os possíveis caminhos, podendo os mesmos ou escolher a mudança, Que ocorre no sentido da verdadeira humanização do homem; ou ficar a favor da permanência, chegando ao ápice da antimudança ${ }^{(1)}$.

Essa mudança de perspectiva na relação do cuidado entre a enfermeira e o usuário é capaz de promover uma autêntica comunicação entre pessoas Que têm sentimentos, desejos, sonhos, dentre outros atributos humanos. Implica em co-construção de saberes e a possibilidade de transformação da realidade; culminando dessa forma, numa interação mútua, verdadeira, horizontal e humanizada, voltada para a libertação dos oprimidos através da ruptura da cultura do silêncio. Esta ação política acontece em comunhão com os oprimidos na busca de sua libertação, resultando em desvelamento e logo, inserção crítica na realidade ${ }^{(2)}$. Sob este prisma, o usuário, na condição de sujeito atua como partícipe do cuidado, decide, opta e escolhe o melhor para si; condição Que vai além de mero receptor de conhecimentos, gerando significativa autonomia nesse processo de modo a reunir condições de implementar o cuidado nos seus espaços de vida comum.

Para isso, se faz necessário acessar os saberes e práticas dos usuários no contexto ambulatorial, de maneira especial, nesta pesQuisa, interessou-nos discutir os saberes e práticas de usuários

\footnotetext{
a Um estoma é uma boca ou abertura. A estomia é uma derivação cirúrgica de uma víscera (geralmente intestino ou vias urinárias) para a pele em um ponto diferente do orifício natural de excreção. O vocábulo "estoma" tem origem grega a partir do étimo "stóma", expõe a idéia de "boca" e possui como sinônimo "estômato".
}

estomizados sobre a manutenção da estomia de eliminação intestinal e urinária, sendo este o objeto de estudo. Objetivos: descrever os saberes e práticas de usuários estomizados sobre a manutenção da estomia de eliminação intestinal e urinária; e analisar a pertinência do compartilhamento de tais saberes e práticas com os cuidados fundamentais de enfermagem, desenvolvidos no contexto ambulatorial.

\section{BASES TEÓRICO-CONCEITUAIS E METODOLÓGICAS}

O estudo teve como base teórica a pedagogia freiriana aplicada à enfermagem. O pensamento de Freire tem colaborado de maneira significativa na construção de uma educação reflexiva na enfermagem, incorporando uma educação crítica e problematizadora, tendo como fio condutor o diálogo com seus educandos; compreendendo o Que é e para Quê serve a educação, indo de encontro à proposta pedagógica monológica e depositária ainda vigente nos dias atuais ${ }^{(3)}$.

Abordagem metodológica Qualitativa desenvolvida em um ambulatório público, municipal, de um Núcleo de Estomizados, localizado na cidade de Campos dos Goytacazes, RJ. Os sujeitos constituíram-se de dez usuários adultos estomizados em acompanhamento ambulatorial, estando com algum tipo de estomia de eliminação intestinal e urinária (íleo/colo/urostomia); com tempo de permanência definitivo ou temporário. Estes usuários, para a inclusão no estudo, deveriam ser os principais responsáveis pelos cuidados relativos à manutenção de sua estomia de eliminação.

O estudo foi aprovado pelo Comitê de Ética em Pesquisa da Escola de Enfermagem Anna Nery/Hospital Escola São Francisco de Assis, da Universidade Federal do Rio de Janeiro, sob Protocolo de $n^{\circ}$ 052/2009. Os sujeitos assinaram um Termo de Consentimento Livre e Esclarecido (TCLE), após terem sido devidamente esclarecidos sobre os aspectos éticos relacionados à sua inserção no estudo, aos objetivos e rumos da pesquisa, bem como às formas de produção de dados.

O método de investigação empregado foi a Pesquisa Convergente-Assistencial $^{(4)}$ (PCA), desenvolvido em Quatro etapas, a saber: 1) Contato "inicial" com o enfermeiro e os auxiliares de enfermagem Que trabalham no ambulatório visando a imersibilidade no serviço. 2) Inserção da pesQuisadora na assistência seguida de caracterização dos sujeitos através de um formulário de identificação do estomizado. 3) Aquecimento e reflexão sobre o tema, feitos antes do início da entrevista, a fim de promover uma estimulação de cada sujeito acerca do tema em pauta, seguida de trocas de experiências com os sujeitos sobre a manutenção da sua estomia de eliminação intestinal e urinária, utilizando como guia um roteiro de entrevista semi-estruturada com Questões-chaves pré-estabelecidas. 4) A última etapa foi o apontamento dos cuidados à luz do Que foi discutido feito simultaneamente à fase anterior.

Os encontros individuais para a produção de dados com os 10 sujeitos foram gravados em meio digital e transcritos na íntegra. A identificação foi feita por códigos alfa-numéricos e os usuários foram identificados pela letra $\mathrm{U}$ e a pesquisadora pela letra P. Após cada letra $\mathrm{U}$ inserida no texto, foram agregados números arábicos seQüenciais, de acordo com a ordem de produção dos dados. Os dados foram analisados e interpretados a partir da triangulação dos achados. Assim, o processo de categorização foi iniciado, a 
partir da análise de conteúdo temática ${ }^{(5)}$.

\section{RESULTADOS E DISCUSSÃO}

\section{Caracterização dos sujeitos do estudo}

Devido à importância do conhecimento prévio da realidade do sujeito, fez-se necessário à descrição dos dados obtidos com o preenchimento do formulário de identificação do estomizado: dos dez usuários participantes, seis eram do sexo feminino e Quatro do sexo masculino. O tempo de confecção do estoma varia de Quatro a 103 meses, média de 46,6 meses. No Que tange à escolaridade, $50 \%$ possuem ensino fundamental incompleto e $10 \%$ ensino fundamental completo; $30 \%$ ensino médio completo; e 10\% ensino superior incompleto. Todos os usuários possuem casa própria, de alvenairia, com luz elétrica e coleta de lixo. O número de moradores por domicílio varia de uma a três pessoas.

Quanto ao tipo de estoma de eliminação, 70\% são de colostomia, 20\% ileostomia, e 10\% urostomia. Sobre o tempo de permanência do estoma de eliminação, $60 \%$ são do tipo temporário e $40 \%$ são permanentes. No Que tange às causas da confecção da estomia de eliminação, 40\% são provenientes de tumor de reto, $20 \%$ doença de Chron, 10\% perfuração por arma de fogo, 10\% abscesso no intestino, 10\% retocolite ulcerativa, e 10\% tumor de bexiga.

É importante considerar Que 90\% dos usuários não recebem ajuda ou apoio de familiares ou vizinhos nos cuidados relativos à manutenção da estomia de eliminação no seu domicílio, enQuanto Que 10\% recebem apoio apenas para colar a bolsa na pele, segundo o relato da usuária, pelo medo de errar e também por causa da dor que sente ao colar (dermatite). Apesar desta problemática singular, um trabalho de enfrentamento foi implementado durante a relação enfermeira-usuária estabelecida no desenvolvimento da pesQuisa, para Que a mesma tente implementar todos os cuidados no seu domicílio e consiga alcançar a autonomia necessária no seu dia-a-dia.

\section{Saberes e práticas de usuários estomizados sobre a manutenção} da estomia de eliminação intestinal e urinária

O conhecimento é a apreensão intelectual de alguma coisa ou objeto ou fenômeno. O processo de conhecer perpassa, durante a história da Humanidade, por todos os povos e culturas, cada qual construindo conhecimentos diferentes para o atendimento de lógicas distintas na constante procura de soluções para a sobrevivência. Estes conhecimentos passados de geração em geração resolvem as necessidades práticas do dia-a-dia, porém não são considerados ou se transformam em conhecimento científico. Isto porQue, cada Qual, a ciência e o senso comum, têm princípios próprios Que os legitimam. O senso comum advém de crenças de sujeitos pertencentes a um grupo ou comunidade onde acontecem as relações sociais, culturais, econômicas e políticas. Isto envolve todo o contexto e realidade subjetiva do indivíduo conhecedor.

A educação em saúde pode ser usada como um artifício para apreendermos esse senso comum, considerando desta forma a subjetividade e o saber de cada sujeito, para assim estabelecermos intercâmbio entre o saber técnico-científico ou profissional e o saber popular advindo do senso comum, construindo então um conhecimento compartilhado.
A informação compartilhada pela ação educativa através da prática dialógica do enfermeiro colabora com Que o usuário exerça sua condição de sujeito, independente e autônomo. Essa forma de educar-cuidar só é possível Quando pensada de forma horizontal, recíproca e verdadeiramente humana a fim de provocar mudança de comportamentos e práticas pela tomada de cons-ciência. Sob esta perspectiva, torna-se viável transformar a posição "ingênua" dos usuários, em posição crítica, em sujeitos mais coerentes e conscientes de sua realidade, participantes do cuidado de maneira ativa, crítica e Questionadora, ampliando as possibi-lidades do cuidado de si. Como seres orgânicos, usuários e profissionais participam da relação de cuidado e estão constantemente se transformando, norteados por pensamentos e ações Que se refazem e se transformam ao longo de suas vidas ${ }^{(6)}$.

Neste estudo revelaram-se alguns saberes e práticas na prática dialógica entre enfermeira-usuário para o desenvolvimento do compartilhamento das experiências sob a tentativa de se construir um plano de cuidados individual e congruente com as necessidades e desejos do usuário. Nesta troca envolvente, emergiram práticas e saberes acerca da troca da bolsa coletora (drenável e não-drenável); manutenção diária da bolsa coletora drenável; irrigação; uso de adjuvantes; complicações tardias (dermatite e prolapso); vida social, familiar e laborativa; religiosidade; sexua-lidade; exercícios e desportos; lazer; vestuário e dieta.

Sobre a troca da bolsa coletora drenável emergiram saberes não só influenciados pelo conhecimento profissional, mas considerados pelas pesquisadoras como pertinentes ao cuidado. Foram relacionados às etapas fundamentais desse cuidado, feito geralmente a cada três dias, a saber: retirada da bolsa de cima para baixo ou de lado para baixo sob o chuveiro, utilizando-se água morna para facilitar o desgaste da cola; ou sobre a cama, deitada, utilizando-se soro fisiológico para ajudar no desprendimento da bolsa. Higienização do local com sabão neutro, de uso habitual ou de coco, com água ou com soro fisiológico a $0,9 \%$. Secagem do local com toalha fraseueira separada apenas para este uso, feita de maneira suave sobre a pele periestomal. Recorte da bolsa Quando a mesma se apresenta recortável, e, Quando pré-recortável, a etapa seguinte se consubstancia em preparar o equipamento para colar de baixo para cima ou de lado para cima, em pé de frente para o espelho ou deitado na cama ou sofá, ambos os modos tendo Que esticar a pele e visualizar o encaixe da colagem.

Neste tipo de cuidado, verificamos a presença de hábitos Que poderiam influenciar a médio/longo prazo o desenvolvimento de complicações tardias, principalmente dermatites irritativas, decorrentes do contato constante do fluido intestinal com a pele em torno do estoma, irritando-a. A prevenção de lesão na pele periestoma deve ser a meta fundamental a ser atingida pelos componentes da equipe multidisciplinar ${ }^{(7)}$. Todos os usuários Que precisavam recortar a bolsa coletora, não medem o estoma frequentemente para o consequente recorte, ou seja, estabelecem e fixam determinada medida, seguindo uma mecanicização contínua desta prática com a mesma numeração de recorte dada. Cons-tatamos Que os usuários, mesmo estando sob cuidados profissionais, no ambulatório, não se conscientizam desta necessidade, talvez pelo fato de Que o saber transmitido pelo profissional tenha um cunho informativo, prescritivo. Assim, os usuários encaram o molde doado para uso no domicílio como um modelo a ser seguido em 
todos os recortes, não se consubstanciando a crítica-reflexão acerca do Que está de fato sendo realizado.

Diante desses eventos, sentimos a necessidade de intervenção durante o diálogo, Que culminou em negociação de um modo de cuidado considerado pelos participantes, adeQuado à situação referida. Nesse sentido, práticas de forçar com gaze a pele periestomal para retirar a cola da mesma, uso constante de éter para ajudar na retirada da bolsa coletora, por exemplo, foram objetos de reflexão e crítica no processo educativo problematizador a partir das Quais emergiram novos saberes, por sua vez, possibilidades de novas práticas.

Os usuários aprovaram a lógica estabelecida no diálogo e, pela reflexão sobre a ação, tomaram consciência da necessidade de alterar as práticas mencionadas. Um exemplo destacado refere-se à UI :

UI: Então, a cola a principio eu estava utilizando as gazes...[risos]. Mas agora eu não utilizo mais. PorQue já conversamos outra vez e você pediu para não utilizar mais com força...aí eu passo o dedo ao redor devagarzinho, bem de levinho.

Outras práticas também fizeram parte da crítica-reflexiva dos usuários, com destaque para soprar o orifício da placa da bolsa, antes da colagem, para o desprendimento do plástico; colar a bolsa não virada para baixo, sentido céfalo-caudal, como é feito no âmbito ambulatorial, nem colocada de lado, da forma realizada no hospital; mas colocá-la de lado, em um ângulo de $45^{\circ}$ direcionada para baixo, com a justificativa de Que, assim, a força da gravidade poderia agir sobre o local, mantendo o efluente de maneira distal.

Segundo o relato dos usuários, a troca da bolsa fechada ou não drenável é realizada por usuários Que utilizam o artifício da irrigação para a manutenção da regularidade do trânsito intestinal e a não saída constante do efluente, e Que não usam o tampão indicado para Quem faz esta prática. O movimento apresentado para a troca deste tipo de bolsa é bem parecido com a drenável, porém a regularidade da troca do equipamento é realizada diariamente ou a cada dois dias de acordo com a necessidade de troca.

A manutenção diária da bolsa coletora drenável foi também revelada pelos usuários de maneira bem espontânea: esta é realizada várias vezes ao dia, de acordo com a necessidade de eliminação do efluente, de diversas formas. A maior parte deles a fazem no banheiro, sobre o vaso sanitário, onde abrem o orifício da bolsa, eliminam o fluido no vaso, injetam água do chuveirinho (Que geralmente se tem ao lado do vaso) e lavam a bolsa. Algumas vezes fecham a bolsa com as próprias mãos para sacudir a água dentro dela e em seguida desprezá-la. Este manejo, segundo o relato dos usuários é feito de forma seQuencial em torno de três vezes. Prestam atenção na limpeza da bolsa e principalmente na retirada de efluente Que se acopla sobre o estoma e pele periestoma. Logo em seguida secam a bolsa e a pele do abdome (se molhadas) e fecham o equipamento com o clamp apropriado.

A irrigação da colostomia também foi um cuidado mencionado por dois usuários, definida como um método mecânico para o controle das exonerações intestinais. Consiste num enema realizado a cada 24, 48 ou 72 horas, cujo fluido, enviado ao intestino grosso através do estoma, estimula sua peristalse em massa e, assim, o esvaziamento do conteúdo fecal. Podemos definí-la portan- to, como uma evacuação programada. A diminuição frequente da flora bacteriana colônica acarreta ainda redução da formação de $\operatorname{gases}^{(7)}$.

Mesmo feita de maneira sistematizada e ter acompanhado as orientações e treinamento realizados no ambulatório, um usuário, segundo seu relato, por não ter se adaptado às orientações dadas no ambulatório, revelou algumas adaptações consideradas pertinentes ao uso, principalmente relacionadas ao sistema coletor:

U5: Aí eu tomo banho, faço a higiene, lavo o estoma e faço a irrigação e seco. Aí pego o meu balde próprio para isso e sento em frente à televisão. Fico ali um pouco.

\section{P: O seu balde é de que tamanho?}

\section{U5: Tamanho normal... Uns 15 litros.}

P: Então, o Senhor já não utiliza o sistema coletor... Como é esse balde?

U5: Já até tentei usar, mas achei muito difícil... Sempre escapava! Se fosse uma coisa mais prática eu usaria com prazer! Não é prático. Mais prático é o balde. Eu uso só para mim... E o balde é bem abauladinho... não machuca! Tem uma bifurcação superior que é onde eu encaixo o estoma e espero o tempo necessário para a eliminação das fezes.

P: Ah sim!!!. Não machuca desta forma! E antes de usar o Senhor lava o balde? Como é Que é?

U5: Lavo o balde bem lavadinho, passo sabão de coco nele e Quando o utilizo espero uma hora e meia mais ou menos... Se eu sentir que o intestino está limpo, não tem mais nada, aí eu tiro o balde.

A autonomia alcançada para o cuidado de si, pela experiência feita, representada nas falas anteriores, é direito do ser humano, porQue há a valorização e concessão da vontade de cada um, mediada pela crítica-reflexão, expressando, deste modo, caráter ético do cuidado, isso porque ser autônomo significa ter liberdade de pensamento, sem coações internas ou externas, poder optar e decidir, entre as alternativas Que dispõe, Qual a Que melhor lhe convém como um ser de relações ${ }^{(8)}$.

O uso de adjuvantes também foi mencionado, principalmente os Que são distribuídos no ambulatório em apreço: barreira protetora de pele em pasta e em pó, além de lubrificante desodorante. Outros adjuvantes também são distribuídos, mas pouco usados ou aceitos pelos usuários. Sobre a forma de utilização destes adjuvantes, os usuários os empregam de maneira apropriada, da forma orientada pelo enfermeiro. Porém, alguns detalhes de utilização não são considerados ou feitos de maneira adequada. Exemplo disto é Quando se utiliza a barreira protetora de pele em pó, para uso em dermatites com umidade; nesta prática, os usuários não retiram o excesso do produto, Queixando-se, posteriormente, de má fixação do equipamento:

P: Você disse que tem uma feridinha em volta do estoma... Você 
utiliza alguma coisa nesta ferida? E você tem umidade na pele por causa da ferida?

U4: Tenho... E utilizava esse pozinho aqui (apontando para o produto sobre a mesa). Mas não utilizo mais... Porque eu boto isso daí e fica saindo, soltando a bolsa!

\section{P: Mas como você coloca esse pozinho?}

U4: Eu coloco em cima da ferida, vou jogando aos poucos e depois colo a bolsa...

P: Mas não tem outra coisa Que você faz nesse processo de jogar o pozinho... E depois de jogar, o que faz?

\section{U4: Colo a bolsa...}

P: Hummm... Não seria interessante então você retirar o excesso desse pozinho com uma gaze sobre a pele machucada, só fazendo um "ventinho" para sair o pó em excesso? (demonstração e explicação de o porQuê e para Quê fazer desta forma).

\section{U4: Hummm... Faz sentido!!! (sorriu).}

A reflexão sobre o cuidado de si é estimulada pela prática educativa da enfermeira, como expresso no diálogo anterior, pois a mesma objetiva facilitar ao máximo o poder de cada sujeito sobre suas vidas através da conscientização, chamando atenção para o fato de Que o sujeito, construtor de sua própria realidade, é capaz de reconstruir e reformular seus conhecimentos ${ }^{(9)}$.

As complicações tardias reveladas foram: dermatite e prolapso. A dermatite foi uma complicação mencionada em maior escala cujas causas foram diversas: troca da bolsa coletora constantemente, fricção exagerada com gaze para retirada de cola sobre a pele, má adaptação às determinadas marcas e/ou tipos de equipamentos, recorte da placa da bolsa feita de maneira inadequada, entre outras. $\mathrm{O}$ tratamento foi feito com uso de adjuvantes indicados por profissionais de saúde ou produtos utilizados para assadura como hipoglós, hipoglós com óleo de amêndoas, e uso de clara de ovo como cicatrizante. Banho de sol também foi um artifício mencionado para a melhora da dermatite. Vejamos alguns fragmentos dialógicos Que tratam disso:

\section{U3: Se eu pegar um sol, logo acaba! Incrível!}

\section{P: É aquilo Que a gente conversou do banho de sol.}

U3: Se eu pegar um sol... porque Quando eu saí do hospital, o médico falou Que eu tenho Que pegar um sol, tomar um banho de sol...

\section{P: Urrumm...}

U3: E Quando eu tomo, num instante, menina, a pele fica limpinha!

UIO: Eu cuidei através do enfermeiro. Vim aQui, mostrei e ele mandou toda vez Que eu trocasse a bolsa passasse uma pomada (barreira protetora de pele em pasta) que ele me deu lá...

\section{P: E você acha que essa pomada faz o Que?}

UIO: ele pediu pra eu passar essa pomada aí pra Que não viesse a irritar a pele. Agora saber mesmo pra Que ela serve...

\section{P: e ela melhorou sua pele?}

UIO: Melhorou porque mandou pegar também um sol e no início andei até fazendo. Porque tinha uma parte lá de casa Que pegava um solzinho..

\section{P: (explicação da indicação da pasta protetora).}

O banho de sol nos remete à precursora da enfermagem moderna, Que lançou as bases da enfermagem como profissão na segunda metade do Século XIX - Florence Nightingale. A autora disserta sobre a natureza e o ambiente que interferem sobremaneira no processo de saúde-doença do sujeito, mencionando o ar puro, claridade, aquecimento, silêncio, limpeza, pontualidade e assistência na ministração da dieta como fatores fundamentais de atenção ao indivíduo sadio ou doente ${ }^{(10)}$. Denota-se na fala de U3 uma constatação enfatizada da efetividade desta prescrição ao mostrar-se satisfeita em perceber Que a orientação deu certo. A enfermeira, no diálogo com U10, ainda explorou como a barreira protetora de pele em pasta atua, destacando Que a melhora da sua dermatite também estava atrelada à prática de banho de sol.

O prolapso foi mencionado por alguns usuários, porém, em menor escala. A forma de lidar com esta problemática, em grande parte, veio pela necessidade de adaptação ao problema exposto, como revelou $\mathrm{U} 8$ :

"Eu fui mesmo aprendendo com o meu dia-a-dia, na minha prática, a melhor forma: com a toalha eu vou apertando ele (prolapso) e fico mexendo nele... Aí ele encolhe e fica pequeninho... aí eu posso secar bem sequinho... porque o prolapso fica batendo na pele e ela fica sempre umidecida. Então eu descobri isso, essa técnica, né (rsrsrs), oito anos né (de estomizada)... a gente vai sempre se descobrindo... Porque eu fiz uma vez... eu toquei e percebi: foi encolhendo".

A construção do cuidado é um processo multifacetado e varia de acordo com a vivência sociocultural e as experiências pessoais. $\mathrm{O}$ fragmento dialógico apresentado anteriormente revela uma extração, pela usuária, de uma situação existencial concreta, dos meios para se haver com a sua realidade de cuidadora, ou seja, de cuidadora de $\mathrm{si}^{(11)}$. Algumas temáticas fizeram parte do movimento do encontro da enfermeira com os usuários: vida sócio-familiar e laborativa; religiosidade; sexualidade; exercícios e desportos; lazer; vestuário e dieta. Durante a prática dialógica entre os partícipes da pesquisa-cuidado estes assuntos foram surgindo e ganhando força. Observa-se diante disto o alcance da problemática de ser/estar estomizado, em Que há interferências e alterações em nível biopsicossocioespiritual.

Os usuários estomizados embora não se constituam expressiva- 
mente do ponto de vista epidemiológico, merecem atenção especial dos profissionais, Serviços e Programas de Saúde, uma vez Que possuem problemáticas de esfera física e psicossocial, levando à necessidade de propostas intervencionistas voltadas para a reabilitação $^{(12)}$. A educação em saúde como prática Que capacita indivíduos e grupos para se auto-organizarem a desenvolver ações a partir de suas próprias prioridades, orienta e estimula à participação dos sujeitos nas ações dirigidas à melhoria de suas condições de vida e saúde ${ }^{(13)}$, pois sua condição de crítica e de reflexão está aguçada; exercendo com maior segurança e autonomia os cuidados relacionados à manutenção de sua estomia, avaliando, modificando hábitos, transformando a realidade.

\section{CONSIDERAÇÕES FINAIS}

Quando se pensa em ações educativas voltadas ao cuidado na manutenção da estomia no contexto ambulatorial, é importante considerar e articular essas ações com o local em Que o cuidado será efetivamente realizado - o domiciliar. Neste espaço, o usuário assume o cuidado. Por isso é importante dialogar com ele acerca de seus saberes e práticas de modo a criar possibilidades de integração destes com aQueles desenvolvidos no contexto ambulatorial. Para tanto, sua participação é imprescindível, pois favorece a crítica e a reflexão e, por conseguinte, a tomada de consciência sobre os caminhos Que podem favorecer ou prejudicar a sua saúde e bem-estar.

Nessa direção, o uso de metodologias participativas de pesQuisa é importante e adequada, uma vez que possuem estreita relação com a prática assistencial. Este tipo de abordagem permite a imersão do pesquisador no processo de assistir, viabilizando o envolvimento ativo dos sujeitos durante todo o seu processo, havendo desta forma, o comprometimento com a melhoria do contexto social pesquisado. De certo modo, esse entrelace vitaliza simultaneamente o trabalho vivo na prática assistencial e na pesQuisa.

Verificamos neste estudo Que os usuários são donos de um saber Que muitas vezes se aproximam do saber profissional, outras vezes de distanciam. Assim, eles observam os cuidados prestados em diferentes cenários da pragmática assistencial: unidades de internação hospitalar, ambulatórios e domicílio; seguem prescrições dos profissionais de saúde à risca e/ou estabelecem adaptações. Além disso, eles acessam o saber advindo do senso comum, transmitido pela herança familiar, de geração em geração, nas relações de vizinhança ou entre os próprios usuários estomizados, fruto da troca de vivências e experiências, tanto no âmbito da Associação de Ostomizados, Quanto em outros espaços de convivência.

A informação compartilhada pela ação educativa através da prática dialógica da enfermeira foi uma estratégia pedagógica Que colaborou para que o usuário exercesse sua condição de sujeito, independente e autônomo. Houve trocas efetivas entre usuários e enfermeira, alcançando-se, desta forma, a comunicação e não uma participação por extensão. A pesQuisa revelou a necessidade de maior divulgação sobre a realidade concreta desses usuários para Que possam sentir-se mais acolhidos, fortificados no enfrentamento das dificuldades Que, porventura, surjam no cotidiano de con(viver) com a derivação cirúrgica.

\section{REFERÊNCIAS}

I. Freire P. Educação e mudança. 20ª ed. São Paulo: Paz e Terra; 1994.

2. Freire P. Pedagogia do oprimido. $12^{\mathrm{a}}$ ed. Rio de Janeiro: Imago; 2001 .

3. Miranda KCL, Barroso MGT. A contribuição de Paulo Freire à prática e educação crítica em enfermagem. Rev Latino-am Enfermagem 2004; 12(4): 631-5.

4. Trentini M, Paim L. Pesquisa convergente-assistencial: um desenho Que une o fazer e o pensar na prática assistencial em saúde-enfermagem. 2a ed. Florianópolis: Insular; 2004.

5. Bardin L. Análise de conteúdo. Lisboa: Edições 70; 2002.

6. Alvim NAT, Ferreira MA. Perspectiva problematizadora da educação popular em saúde e a enfermagem. Texto Contexto Enferm 2007; 16(2): 315-19.

7. Santos VLCG, Cesaretti IUR. Assistência em estomaterapia: cuidando do ostomizado. São Paulo: Editora Atheneu, 2005.

8. Soares NV, Lunardi VL. Communication, the information as a possibility for reducing the asymmetry between the health pro-

fessional and the client. In: Proceedings of the $8^{\text {th }}$ Brazilian Nursing Communication Symposium [Proceedings online]; 2002 May 02-03; São Paulo, SP, Brazil. 2002 [cited 2009 Aug 3 1]. Available from: http://www.proceedings.scielo.br/

9. Freitas FV, Sabóia VM. Vivências de adolescentes diabéticos e contribuições da prática educativa da enfermeira. Rev Enferm UERJ 2007; 15(4): 569-73.

10. Nightingale F. Notas sobre enfermagem: o que é e o Que não é. São Paulo: Cortez; 1989.

1 1. Coelho GS, Alvim NAT. A dinâmica familiar, as fases do idoso com Alzheimer e os estágios vivenciados pela família na relação do cuidado no espaço domiciliar. Rev Bras Enferm 2004; 57(5): 54 I-4.

12. Santos VLCG. Fundamentação teórico-metodológica da assistência aos ostomizados na área da saúde do adulto. Rev Esc Enferm USP 2000; 34(1): 59-63.

13. Fernandes MCP, Backes VMS. Educação em Saúde: perspectivas de uma equipe da Estratégia Saúde da Família sob a óptica de Paulo Freire. Rev Bras Enferm 2010; 63(4): 567-73. 